\title{
Genetic analysis for physical nut traits in almond
}

\section{Angel Fernández i Martí · Carolina Font i Forcada · Rafel Socias i Company}

A. Fernandez i Marti • C. Font i Forcada - R. Socias i Company ()

R. Socias i Company Unidad de Fruticultura, Centro de Investigacion y Tecnologia Agroalimentaria de Aragon (CITA)

Av. Montanana 930; 50059 Zaragoza, Spain e-mail: rsocias@aragon.es

A. Fernandez i Marti*

Present Address: Laboratorio de Mejora Genetica y Biologia Molecular, Parque Cientifico Tecnologico de Aula Dei (PCTAD) Av. Montanana 930; 50059 Zaragoza, Spain e-mail: afernandez@pctad.com

C. Font i Forcada* Present Address: Unidad de Pomologia, Estacion Experimental de Aula Dei (EEAD-CSIC) Apartado 13034; 50080 Zaragoza, Spain e-mail: cfont@eead.csic.es

*A. Fernandez i Marti and C. Font i Forcada contributed equally to this work 


\begin{abstract}
Almond breeding is increasingly taking into account kernel quality as a breeding objective. Although information on nut and kernel physical parameters involved in almond quality has already been compiled, the genetic control of these traits has not been studied. This genetic information would improve the efficacy of almond breeding programs. A linkage map with 56 simple-sequence repeat markers was constructed for the "Vivot" $\times$ "Blanquerna" almond population showing a wide range of variability for the physical parameters of nut and kernel. A total of 14 putative quantitative trait loci (QTLs) controlling these physical traits were detected in the current study, corresponding to six genomic regions of the eight almond linkage groups (LG). Some QTLs are colocated in the same region or shared the same molecular markers, in a manner that reflects the correlations between the physical traits, as well as with the chemical components of the almond kernel. The limit of detection values for any given trait ranged from 2.06 to 5.17, explaining between 13.0 and $44.0 \%$ of the phenotypic variance of the trait. This new genetic information needs to be taken into account when breeding for physical traits in almond. Increases in the positive quality traits, both physical and chemical, need to be considered simultaneously whenever they are genetically independent, even if they are negatively correlated. This is the first complete genetic framework map for physical components of almond nut and kernel, with 14 putative QTLs associated with a large number of parameters controlling physical traits in almond.
\end{abstract}

\title{
Key words
}

Breeding - Prunus amygdalus Batsch • Nut traits • Kernel traits • QTL analysis • Genomics 


\section{Introduction}

Almond [Prunus amygdalus Batsch, syn. Prunus dulcis (Mill.) D.A. Webb] is a major tree nut grown in areas with Mediterranean climate. As in any other crop, fruit quality is an important breeding goal despite the difficulties in defining a quality ideotype due to differences in consumer preferences (Janick 2005). Although quality is often related to the chemical composition of any fruit, including the nutritional and health aspects involved in defining its final value, some physical parameters must also be taken into account when evaluating quality. The physical traits of almond nut do not affect the organoleptic characteristics of the kernel but have a special importance in the industry because of the different steps involved in almond processing (Socias i Company et al. 2008).

Almond breeding has until recently focused on selecting self-compatible and late-blooming cultivars with excellent physical attributes (Socias i Company et al. 2012). In addition to the sweet/bitter taste, the physical parameters were the only ones so far considered in almond evaluation, and their heritabilities were determined (Kester et al. 1977). However, the physical traits of nuts and kernels were only considered as morphological traits for almond cultivar characterization, but not as quality traits. Some physical traits, however, require a more detailed examination, especially those related to the shell, since the shell has never been considered as a component of almond quality (Socias i Company et al. 2009).

The shell was probably neglected because it is not related to the chemical composition or to the organoleptic quality of the kernel. Nevertheless, the shell plays an important role during harvest and industrial processing and therefore should be taken into account when evaluating an almond cultivar. Softshell cultivars possess such a soft and thin shell that sometimes is not well sealed through the suture line, where abortion of the secondary ovule has taken place (Gradziel and Martínez-Gómez 2002), leaving an entry point for dust, insects, and fungi. This contamination may be further aggravated by the presence of Aspergillus among the contaminating fungi and the production of the toxic aflatoxins and other carcinogenic and immunosuppressive mycotoxins (Dicenta et al. 2002; Gradziel and Wang 1994). However, depending on the industry of each region, a different type of shell is preferred, hard in most Mediterranean countries and soft in California.

The size and shape of the nut must be taken into account for designing and adjusting appropriate technologies for harvesting, dehulling, transporting, classifying, processing, and storing the crop. Additionally, the size and shape of the kernel may define its utilization in specific commodities, such as chocolate bars, sugared almonds, and sliced kernels. Although the physical parameters of the nut and the kernel have been scarcely considered as an objective in almond breeding, their relevance stresses the need to consider them as part of the evaluation criteria for almond quality in a breeding program (Socias $\mathrm{i}$ Company et al. 2009).

Among the physical traits, in addition to the attractiveness of the kernel, only shell hardness and the presence of double kernels have received some attention, mainly because of the specific requirements of the cracking process. Although the heritability of most of the physical parameters of almond nut and kernels is already known (see Socias i Company et al. 2012 for a review), not much is known about the genetics of these traits. Only the phenotypic correlation among some traits has been studied (Sánchez-Pérez et al. 2007a) and the independence of the physical and chemical traits has been established (Kodad and Socias $i$ Company 2006). This scarce information requires deeper genetic examination in order to fully utilize these 
traits in a breeding program.

Simple-sequence repeat (SSR) or microsatellite markers have recently become a very useful tool for constructing linkage maps and for locating genes controlling phenotypic variability. The development of markers associated with a trait may improve the speed and precision of breeding programs with the aim of selecting for this trait by marker-assisted selection. The first attempt to map agronomic traits in almond was undertaken by Sánchez-Pérez et al. (2007b), but these authors studied only a few physical traits including nut and kernel weight and shell hardness. The availability of the almond cross "Vivot" $\times$ "Blanquerna" ("V $\times$ $B^{\prime \prime)}$ made it possible for us to generate a linkage map of this population (Fernández i Martí et al. 2011), as well as determine 20 physical parameters of nuts and kernels (Font i Forcada 2008). Our objective in the present study was to identify quantitative trait loci (QTLs) associated with physical parameters of almond nut and kernel in order to develop a genetic framework for use in an almond breeding program to improve the physical quality of almond.

\section{Materials and methods}

\section{Plant material and DNA isolation}

The offspring studied include 62 individuals from the cross $V \times B$ obtained in the CITA almond breeding program of Zaragoza, Spain. The female parent Vivot is a Spanish local cultivar, and the male parent Blanquerna is a release from this program, obtained from "Genco" $\times$ "AS-1" pollination (Socias i Company and Felipe 1999; Fernández i Martí et al. 2009). These parents were selected because of their interesting characteristics, such as nut quality and medium-late blooming (Felipe 2000). This progeny is maintained as living plants in a nursery row using standard management practices, close to the parents, which belong to the Spanish almond germplasm collection located at $41^{\circ} 38^{\prime} \mathrm{N}$ and $0^{\circ} 53^{\prime} \mathrm{W}$, at $220 \mathrm{~m}$ above sea level, at Zaragoza, Spain. The total genomic DNA was isolated using the procedure described by Doyle and Doyle (1987). The DNA was quantified and diluted to $10 \mathrm{ng} \mu \mathrm{L}-1$ for PCR amplifications.

\section{Physical determinations}

The physical parameters selected for measurement were those significant for almond processing (Aydin 2003). Fifty mature fruits were collected at random from each genotype. The fruit was considered mature when the mesocarp was fully dry and split along the fruit suture and the peduncle was near to complete abscission (Felipe 2000). After discarding the mesocarp, the nuts were left at room temperature for 2-3 weeks, as described by Font i Forcada et al. (2011). After taking nut measurements, shells were cracked to obtain the kernel. Nut and kernel weights were obtained using an electronic balance. The lineal parameters, length (L), width (W), and thickness $(T)$, were measured with a digital caliper with a precision of $0.01 \mathrm{~mm}$. These variables allowed to determine the $W / L, T / L$, and $L / W$ ratios; the size $(L \times W \times T)$; the geometric diameter $(L \times W \times T) 1 / 3$; and the spherical index (geometric diameter/L). These parameters were determined both for the nut and the kernel. The average values of the results of 2 years were used for analysis. The absence of any year effect was confirmed by the lack of significant differences between the values of the 2 years. 
DNA marker genotyping, genetic mapping, and QTL analysis

A total of 110 SSR markers previously described in other Prunus species (Table 1 ) were tested in the $V \times B$ almond progeny to identify polymorphic markers between the two parents, providing a good coverage of the Prunus bin mapping " $\mathrm{T} \times \mathrm{E}$ " (Howad et al. 2005). Those heterozygous in one or both parents and resulting in a good coverage of the $T \times E$ Prunus reference map were selected for analysis in the whole population. From the initial V × B map (Fernández i Martí et al. 2011), eight SSRs designed from other Prunus species were additionally PCR-amplified in order to be included in the previous map, using the same conditions (Table 1). Among these eight SSRs, only four, the heterozygous ones, were placed in the map (СРРCT022, СРDCT027, ВРРСТ015, and СРРСТ058).

PCR reactions were performed in a $10-\mu \mathrm{L}$ volume, and the reaction mixture contained $1 \times$ PCR buffer (Invitrogen, Barcelona, Spain), $1.5 \mathrm{mM} \mathrm{MgCl2}, 0.2 \mathrm{mM}$ dNTPs, $0.2 \mu \mathrm{M}$ of each primer, 1 unit of Taq DNA Polymerase (Invitrogen), and $20 \mathrm{ng}$ of genomic DNA. The cycling parameters include denaturation for $1 \mathrm{~min}$ at $94{ }^{\circ} \mathrm{C}, 35$ cycles of $15 \mathrm{~s}$ at $94^{\circ} \mathrm{C}, 15 \mathrm{~s}$ for the corresponding annealing temperatures and $1 \mathrm{~min}$ at $72{ }^{\circ} \mathrm{C}$, followed by a final extension of $2 \mathrm{~min}$ at $72{ }^{\circ} \mathrm{C}$. The PCR reactions were carried out in a 96-well block Thermal cycler (Applied Biosystems, Madrid, Spain). PCR products were detected using an ABI PRISM 3130xI Genetic Analyzer and GeneMapper analysis software (Applied Biosystems). For capillary electrophoresis detection, forward SSR primers were labeled with 5'-fluorescence dyes PET, NED, VIC, and 6-FAM and the size standard used in the sequencer was GeneScan ${ }^{\mathrm{TM}} 500$ LIZ $^{\circledR}$ (Applied Biosystems).

We constructed a map for each parent, as if they were backcross one segregations using directly the markers segregating 1:1, converting the 1:1:1:1 into two 1:1 segregations (one for each parent) and using only the two homozygous classes of the 1:2:1 segregations. Composite interval mapping was used for mapping QTLs (MapQTL 4.0) (Van Ooijen et al. 2002). The limit of detection (LOD) threshold of $\geq 2.0$ was established for significance of a QTL.

\section{Results and discussion}

Genetic variability for physical traits in almond

The phenotypic variability and the frequency distributions for the physical components of the almond kernel and nut are shown in Table 2 and Figs. 1 and 2. Most traits evaluated showed a normal distribution, although for some traits, such as nut $T / L$ ratio and kernel width, the distribution was skewed. The values of the parents were in the range of variability of the progeny, but for all the traits related to nut and kernel size (the three primary dimensions and weight), the parents' mean was away from the progeny mean. This deviation would be expected in traits subjected to constant breeding selection, as kernel size has been for a long time. Despite this deviation, some seedlings showed in all cases higher values than the best parent, thus opening up the possibility for improvement through breeding.

Despite the similarity of the parents for many traits, this progeny showed a wide range of variability, although it cannot be compared with other populations. The only other genetic analysis of QTLs linked to the size of the almond nut and kernel (Sánchez-Pérez et al. 2007b) did not show the variability of the progeny. 
Linkage map of QTLs controlling the physical components of the almond kernel and nut

The population studied was selected because of the wide range of variability of physical components of the nuts and kernels. A map from this population had already been published (Fernández i Martí et al. 2011) and was used for detecting QTLs controlling physical traits of the almond nuts and kernels. This map, previously constructed with 52 SSR markers, has been increased with four more SSRs, representing a total of 56 markers (Table 1). The position of these markers (Fig. 3) agrees with the last almond map published (Tavassolian et al. 2010). A LOD score of 2.0 was used to establish the presence of a QTL linked to the traits studied (width, thickness, length, weight, geometric diameter, spherical index, size, L/W, T/L, and W/L). A total of 14 putative QTLs controlling these traits were detected in this analysis, corresponding to six genomic regions of the eight almond linkage groups (LGs). Only LG4 and LG8 did not show any QTL for almond nut and kernel traits. Some QTLs were clustered in the same region and/or shared the same molecular markers (Table 3). The LOD values for any given trait ranged from 2.06 to 5.17, explaining 13.0 to $44.0 \%$ of the phenotypic variance of the trait.

QTLs for primary dimension (width, thickness, and length)

Eight QTLs controlling the traits of nut width, thickness, and length were detected in LG1, LG2, LG3, LG5, LG6, and LG7 (ВPPCT020a, UDP98-025, BPPCT007, UDP96-008, СРSCT006, UDP98-412, СРPCT033, and PMS02) (Table 3, Fig. 3). The LOD of all traits studied ranged from 2.17 (PMSO2) to 4.56 (BPPCTO20a), and the percentage of phenotypic variance ranged from $15 \%$ (PMSO2) to $30.6 \%$ (BPPCTO20a).

In addition, eight QTLs were detected for the same kernel traits in LG1, LG3, LG5, LG6, and LG7 (CPPCT042, UDP96-008, ВРPCT017, СРSСT006, ВРPСT020b, UDP98-412, СРРСТ039, and PMS02). Some of these QTLs shared the same locus for both nut and kernel (UDP96-008, CPSCT006, UDP98-412, and PMS02). The LOD of these three kernel traits ranged from 2.13 (PMS02) to 4.63 (UDP96-008). The percentage of phenotypic variance ranged from $13.5 \%$ (BPPCT020b) to $30.6 \%$ (UDP96-008). All LODs and percentages of variance explained are summarized in Table 2, giving the first information on QTLs linked to the primary dimensions of the almond nut and kernel. Nut and kernel primary dimensions are correlated, but not conclusively (Kester et al. 1993; Kodad and Socias i Company 2006). Our results coincide with this assertion as the same dimension for nut and kernel is not always controlled by the same QTL. Only four QTLs are controlling the same dimension for nut and kernel. Nut and kernel width is linked to UDP96-008 marker, while nut and kernel length is linked to CPSCT006, UDP98-412, and PMS02 markers.

QTLs for weight and size

Three QTLs were detected for nut weight and size at the beginning of LG1 (BPPCT020a, LOD of 2.47), LG2 (UDP98-025, LOD of 4.89), and LG7 (CPPCT033, LOD of 2.79). For kernel weight and size, not only the same QTL in LG7 (СPPCT033) was detected but also a new QTL for weight in LG7 (CPSCT004) with a LOD of 2.90 (Table 3, Fig. 2). The total phenotypic variation for weight in nut and kernel was 44.6 and $14.4 \%$, respectively, whereas for size, it was 30.4 and $16.2 \%$, respectively. Only Sánchez-Pérez et al. (2007b) had previously conducted nut weight examination, with two QTLs on LG1 and LG2 in the progeny "R × D." These two QTLs are located in the same position as ours, thus confirming the results. There is no previous information on QTLs linked to nut and kernel size. In other Prunus species, very few studies have been carried out for fruit weight and size. In sweet cherry, Zhang et al. (2010) identified three QTLs linked to fruit size on LG2 and LG6 using SSR markers, whereas in peach, one QTL linked to fruit weight was detected on LG1 by Abbott et al. (1998) using RFLP, AFLP, RAPD, and SSR markers. 
A total of ten QTLs were detected for spherical index, geometric diameter, and $L / W, T / L$, and $W / L$ ratios, both in the nut and the kernel. Four QTLs were identified for the nut spherical index in LG2 (UDP98-025, LOD of 3.17), LG3 (BPPCT007, LOD of 2.17; UDP96-008, LOD of 2.34), and LG7 (СPPCT033, LOD of 3.23) (Table 3, Fig. 3). Their total phenotypic variation was $69.4 \%$. For the kernel spherical index, only one QTL was identified on LG7 (CPPCT033, LOD of 2.80). Two QTLs were identified for nut geometric diameter, one on LG2 (UDP98-025, LOD of 2.71) and the other on LG6 (UDP98-412, LOD of 2.20). Two different QTLs were identified for the kernel geometric diameter, one on LG1 (BPPCTO20a, LOD of 2.10) and the other on LG7 (CPPCT033, LOD of 3.12). Their total phenotypic variation for nut and kernel was $61.9 \%$. These two traits are related to nut and kernel shape, which is a rather constant parameter despite the variation in size (Kodad and Socias i Company 2006). However, only one QTL (CPPCT033) has been shown to be significant for the same trait (spherical index) in the nut and the kernel.

For the nut T/L ratio, three QTLs were located, one on LG1 (СPPCT042, LOD of 4.81), another on LG5 (CPSCT006, LOD of 3.57), and the third on LG7 (CPPCT033, LOD of 3.33). Their total phenotypic variation was $35,22.3$, and $23.7 \%$, respectively. The kernel T/L ratio was controlled by two QTLs, one located on LG1 (CPPCT042, LOD of 4.40), explaining a phenotypic variation of $20 \%$, and another on LG2 (UDP96-013, LOD of 3.10), explaining $19.6 \%$ of the phenotypic variation (Table 2, Fig. 1). Four QTLs were identified for the nut and kernel L/W ratio, one on LG7 (CPPCT033, LOD of 2.13), one on LG2 (UDP96-013, LOD of 3.70), one on LG3 (UDP96-008, LOD of 5.17), and the last on LG6 (BPPCT020b, LOD of 2.58), explaining most of the phenotypic variation (R 2 of 76.7). Also, four QTLs were located for the nut $W / L$ ratio on three different linkage groups (LG1, LG5, and LG7). The nearest markers were BPPCT020a (LOD of 4.0) and CPPCT042 (LOD of 4.0) on LG1, CPSCT006 (LOD of 3.34) on LG5, and CPPCT033 (LOD of 3.45) on LG7, explaining a phenotypic variation of $96.5 \%$. For the kernel W/L ratio, only one QTL was detected, CPPCT033 on LG7, with a LOD of 4.30 and explaining a phenotypic variation of $22.7 \%$. However, only two QTLs have been shown to be significant for the same trait in the nut and the kernel. The CPPCT042 marker was linked to the T/L ratio for nut and kernel whereas the СРРСТ033 marker was linked to the W/L ratio for nut and kernel.

Correlations between the physical traits in almond

Table 4 shows the phenotypic correlations among the nut and kernel traits in almond. The three primary nut dimensions (length, width, thickness) were significantly correlated between them $(0.88,0.64,0.52)$, as well as with weight $(0.77,0.89,0.82)$, geometrical diameter $(0.84,0.93,0.85)$, spherical index $(0.61,0.98,0.95)$, and size $(0.84,0.93,0.85)$. Weight showed positive and significant correlations with geometrical diameter (0.94), spherical index (0.89), and size (0.94). Also, geometrical diameter was correlated significantly with spherical index (0.94) and size (0.99). The derived ratios $\mathrm{L} / \mathrm{W}, \mathrm{T} / \mathrm{L}$, and $\mathrm{W} / \mathrm{L}$ were negatively correlated with length $(-0.44,-0.73,-0.55)$, weight $(-0.59)$, geometrical diameter $(-0.51,-0.27)$, and size $(-0.51,-0.27)$. The highest correlations for nut traits were found between width and spherical index (0.98), and between size and geometrical diameter (0.99). All these correlations were expected to be involved in establishing the final size of the nut.

The three primary kernel dimensions were also positively and significantly correlated among them $(0.35$, $0.44,0.42)$. Weight showed significant correlations with width $(0.29)$, length $(0.43)$, size $(0.51)$, geometrical diameter (0.51), and spherical index (0.40); size showed significant correlations with width (0.75), length (0.79), geometrical diameter (0.99), and spherical index (0.83). Also, width, thickness, and length of kernel 
showed positive and significant correlations with geometrical diameter $(0.75,0.79)$ and spherical index $(0.75,0.47,0.32)$. The derived dimensions $\mathrm{T} / \mathrm{L}$ and $\mathrm{L} / \mathrm{W}$ were negatively correlated with length $(-0.79,-0.34)$, width $(-0.44,-0.84)$, geometrical diameter $(-0.43,-0.40)$, spherical index $(-0.30)$, and size $(-0.43,-0.40)$ (Table 4). The highest correlations were found between size and geometric diameter $(r=0.99, P \leq 0.05)$, between size and spherical index $(r=0.83, P \leq 0.01)$, and between geometric diameter and spherical index $(r=0.83, P \leq 0.01)$. As expected, the most important correlations were found between the same nut and kernel traits, as already reported by Kester et al. (1993) and Kodad and Socias i Company (2006).

\section{Correlations between physical and chemical traits in almond}

Almond quality is defined by both chemical and physical traits (Socias i Company et al. 2008). Consequently, both kinds of traits must be considered simultaneously because a breeding program may require the improvement of both physical and chemical traits (Kodad and Socias i Company 2006). Some chemical traits have already been considered from a breeding point of view, including the correlations among them and showing significant correlations with physical traits (Kodad et al. 2006; Font i Forcada et al. 2011, 2012). Table 5 shows the phenotypic correlations between chemical and physical traits in almond. The highest positive correlations found were between protein content and nut length (0.61), weight (0.51), geometrical diameter (0.52), and size (0.52). Oil content was highly and positively correlated with nut length $(0.42)$ and size $(0.38)$ and highly and negatively with geometrical diameter $(-0.38)$ and spherical index $(-0.30)$. The most significant and negative correlations were found between palmitic acid and nut thickness $(-0.48)$, and the $\mathrm{T} / \mathrm{L}(-0.52)$ and $\mathrm{W} / \mathrm{L}(-0.46)$ ratios, as well as between stearic acid and nut width $(-0.47)$. Positive correlations were also found between oleic acid and nut width (0.28), thickness (0.40), weight $(0.24)$, spherical index (0.35), $\mathrm{T} / \mathrm{L}(0.30)$, and $\mathrm{W} / \mathrm{L}(0.29)$. Negative correlations were found between linoleic acid and nut width $(-0.27)$, thickness $(-0.38)$, weight $(-0.25)$, spherical index $(-0.33), T / L(-0.28)$, and $\mathrm{W} / \mathrm{L}(-0.27)$. For the tocopherol homologues, only $\gamma$ - and $\delta$-tocopherols were negatively correlated with the nut L/W $(-0.30$, $-0.34)$ and $T / L(-0.32)$ ratios.

For the kernel traits, negative and significant correlations were found between thickness and $\alpha-(-0.29), \nu^{-}$ $(-0.27)$, and $\delta$-tocopherols (-0.30). All fatty acid (except oleic), oil, and protein contents were negatively correlated with kernel width $(-0.28,-0.26,-0.36,-0.32,-0.27,-0.34)$. Significant and positive correlations were found between kernel length and protein content $(0.63)$, oil content $(0.43)$, palmitic acid $(0.25)$, stearic acid (0.38), and palmitoleic acid (0.41). Kernel weight and size were significantly correlated with protein content and oil $(0.37,0.36,0.63,0.40)$. For the other traits, the most significant and highest correlations were found between protein content and kernel length and geometric diameter (0.63).

\section{Relationships of QTLs linked to chemical and physical traits in almond}

Correlations between the chemical and physical parameters controlling the same QTL were observed in five of the eight almond LGs (LG1, LG2, LG3, LG6, and LG7). Two QTLs were detected on LG1, one close to the locus BPPCTO20a and the other near CPPCT042. The traits controlled by these two loci were significantly correlated. For the first QTL, $\delta$-tocopherol was negatively and significantly correlated with the nut $T / L$ ratio (0.32). For the second $Q T L$, stearic acid was negatively correlated with the nut $T / L$ and $W / L$ ratios $(-0.35$, -0.35 ) and positively correlated with kernel length (0.38). For the first QTL, $\delta$-tocopherol was negatively and significantly correlated with the nut $\mathrm{T} / \mathrm{L}$ ratio $(-0.32)$.

On LG2, one QTL near the locus UDP98-025 showed significant correlations with quality traits. Oleic acid was positively correlated with nut width (0.28), thickness $(0.40)$, weight $(0.24)$, and spherical index $(0.35)$. No 
significant correlations were found for the nut geometric diameter and size. Linoleic acid showed negative correlations with nut width $(-0.27)$, thickness $(-0.38)$, weight $(0.25)$, and spherical index $(0.33)$, as expected because of its negative correlation with oleic acid (Font i Forcada et al. 2011).

One QTL near the locus BPPCT007 was identified on LG3 controlling several traits. Palmitic acid was negatively correlated with nut width $(-0.27)$ and spherical index $(-0.37)$. Nut width was also positively and highly correlated with the nut spherical index $(0.98, \mathrm{P} \leq 0.01)$.

On LG6, the QTLs close to the locus UDP98-412 correlated positively and significantly with stearic acid and nut and kernel length, as well as with total protein content and nut and kernel length. Additionally, a significant correlation was found between nut geometric diameter and protein content.

On LG7, significant correlations were found between traits positioned near the marker СРPCT033. Negative correlations were found between $\delta$-tocopherol and palmitic, stearic, and linoleic acids and positive with oleic acid (Font i Forcada et al. 2011). Negative but low correlations were found between $\delta$-tocopherol and the nut L/W (0.34) and T/L ratios (0.32). No significant correlations were found between $\delta$-tocopherol and the other traits. Positive and low correlations were found between oleic acid and nut thickness $(0.40)$, spherical index (0.35), T/L (0.30), and W/L (0.29), as well as with kernel spherical index and W/L ratio (0.44). Negative and low correlations were found between linoleic, palmitic, and palmitoleic acids with nut thickness, spherical index, and $\mathrm{T} / \mathrm{L}$ and $\mathrm{W} / \mathrm{L}$ ratios, as well as between these fatty acids and kernel $\mathrm{W} / \mathrm{L}$ ratio (Table 5 ). A negative and significant correlation was found between stearic acid and kernel geometrical diameter $(-0.27)$ and a positive correlation between stearic acid and kernel size (0.27). A negative correlation was found between linoleic acid and kernel spherical index $(-0.27)$.

Despite the high number of correlations between physical and chemical traits in almond, the correlation between two different traits does not always match with the same QTL controlling these traits. This lack of coincidence shows that the two traits are genetically independent. Consequently, these trait types may be improved simultaneously, even if they are negatively correlated. Thus, the high complexity of an almond breeding program aiming at the addition of positive traits may be simplified with the help of this new knowledge.

\section{Conclusion}

Fourteen QTLs associated with the physical traits of the almond nut and kernel were identified. At least one QTL was correlated with each trait with a significant probability $(P \leq 0.05)$. Among these physical traits, nine (width, thickness, length, geometric diameter, size, spherical index, L/W, $T / L$, and $W / L$ ) have been now studied for the first time in almond.

The results of this study, together with the knowledge acquired on the chemical components of the almond kernel, may allow a more sound almond breeding program, not only taking into account that quality is an increasing objective in almond breeding but also that the physical and chemical traits may be improved simultaneously. The genetic information obtained after mapping these QTLs may be a very useful tool in attaining this breeding objective. 


\section{Acknowledgments}

This research was funded by the Spanish grant AGL2010-22197-C02-01 and the Research Group A12 of Aragón. Dr. Pere Arús and Dr. Werner Howad (IRTA-CSIC, Barcelona) are thanked for their assistance in the mapping analysis with MapMaker, JoinMap, and MapQTL. Dr. Ossama Kodad is thanked for his help with the physical analyses.

\section{References}

Abbott AG, Rajapakse S, Sosinski B, Lu ZX, Sossey-Alaoui K, Gannavarapu M, Reighard G, Ballard RE, Baird WV, Scorza R, Callahan A (1998) Construction of saturated linkage maps of peach crosses segregating for characters controlling fruit quality, tree architecture and pest resistance. Acta Horticult 465:41-49

Aranzana MJ, Garcia-Mas J, Carbó J, Arús P (2002) Development and variability analysis of microsatellites markers in peach. Plant Breed 121:87-92

Aydin C (2003) Physical properties of almond nut and kernel. J Food Eng 60:315-320

Cantini C, lezzoni AF, Lamboy WF, Boritzki M, Struss D (2001) DNA fingerprinting of tetraploid cherry germplasm using SSR. J Am Soc Hortic Sci 126:205-209

Cipriani G, Lot G, Huang HG, Marrazzo MT, Peterlunger E, Testolin R (1999) AC/GT and AG/CT microsatellite repeats in peach (Prunus persica (L.) Batsch): isolation, characterization and cross-species amplification in Prunus. Theor Appl Genet 99:65-72

Dicenta F, Martínez-Pato E, Martínez-Gómez P (2002) Behaviour of almond cultivars in the presence of Aspergillus flavus Link. Acta Horticult 591:561-564

Dirlewanger E, Cosson P, Travaud M, Aranzana MJ, Poizat C, Zanetto A, Arús P, Laigret F (2002) Development of microsatellite markers in peach [Prunus persica (L.) Batsch] and their use in genetic diversity analysis in peach and sweet cherry (Prunus avium L.). Theor Appl Genet 105:127-138

Downey LD, lezzoni AF (2000) Polymorphic DNA markers in cherry are identified using sequences from sweet cherry, peach, and sour cherry. J Am Soc Hortic Sci 125:76-80

Doyle JJ, Doyle JL (1987) A rapid DNA isolation procedure for small quantities of fresh leaf tissue. Phytochem Bull 19:11-15

Felipe AJ (2000) El almendro: el material vegetal. Integrum, Lérida

Fernández i Martí A, Alonso JM, Espiau MT, Rubio-Cabetas MJ, Socias i Company R (2009) Genetic diversity in Spanish and foreign almond germplasm assessed by molecular characterization with SSRs. J Am Soc Hortic Sci 134:535-542

Fernández i Martí A, Howad W, Tao R, Alonso JM, Arús P, Socias i Company R (2011) Identification of qualitative trait loci associated with self-compatibility in a Prunus species. Tree Genet Genome 7:629-639 
Font i Forcada C (2008) Estudio de la variabilidad y de la heredabilidad de la composición de la almendra como criterio de la mejora para la calidad. MSc Thesis, IAMZ/CIHEAM, Zaragoza, Spain

Font i Forcada C, Kodad O, Juan T, Estopañán G, Socias i Company R (2011) Genetic variability and pollen effect on the transmission of the chemical components of the almond kernel. Span J Agric Res 9:781-789

Font i Forcada C, Fernández i Martí A, Socias i Company R (2012) Mapping quantitative trait loci for kernel composition in almond. BMC Genet 13:47

Gradziel TM, Martínez-Gómez P (2002) Shell seal breakdown in almond is associated with the site of secondary ovule abortion. J Am Soc Hortic Sci 127:69-74

Gradziel TM, Wang D (1994) Susceptibility of California almond cultivars to aflatoxigenic Aspergillus flavus. HortSci 29:33-35

Howad W, Yamamoto T, Dirlewanger E, Testolin R, Cosson P, Cipriani G, Monforte AJ, Georgi L, Abbott AG, Arús $P$ (2005) Mapping with a few plants: using selective mapping for microsatellite saturation of the Prunus reference map. Genetics 171:1305-1309

Janick J (2005) Breeding intractable traits in fruit crops: dream the impossible dream. Introduction. HortSci 40:1944

Kester DE, Hansche PE, Beres W, Asay RN (1977) Variance components and heritability of nut and kernel traits in almond. J Am Soc Hortic Sci 102:264-266

Kester DE, Cunningham S, Kader AA (1993) Almonds. In: Encyclopedia of food science, food technology, and nutrition. Academic, London, pp 121-126

Kodad O, Socias i Company R (2006) Influence of genotype, year and type of fruiting branches on the productive behaviour of almond. Sci Hortic 109:297-302

Kodad O, Socias i Company R, Prats MS, López Ortiz MC (2006) Variability in tocopherol concentrations in almond oil and its use as a selection criterion in almond breeding. J Hortic Sci Biotechnol 81:501-507

Mnejja M, Garcia-Mas M, Howad W, Badenes ML, Arús P (2004) Simple sequence repeat (SSR) markers of Japanese plum (Prunus salicina Lindl.) are highly polymorphic and transferable to peach and almond. Mol Ecol Notes 4:163-166

Sánchez-Pérez R, Ortega E, Duval H, Martínez-Gómez P, Dicenta F (2007a) Inheritance and relationships of important agronomic traits in almond. Euphytica 155:381-391

Sánchez-Pérez R, Howad W, Dicenta F, Arús P, Martínez-Gómez P (2007b) Mapping major genes and quantitative trait loci controlling agronomic traits in almond. Plant Breed 126:310-318

Socias i Company R, Felipe AJ (1999) 'Blanquerna', 'Cambra' y 'Felisia': tres nuevos cultivares autógamos de almendro. Inf Técn Econ Agrar 95V:111-117

Socias i Company R, Kodad O, Alonso JM, Gradziel TM (2008) Almond quality: a breeding perspective. Hortic Rev 34:197-238 
Socias i Company R, Alonso JM, Kodad O (2009) Fruit quality in almond: physical aspects for breeding strategies. Acta Horticult 814:475-480

Socias i Company R, Alonso JM, Kodad O, Gradziel TM (2012) Almond. In: Badenes ML, Byrne D (eds) Fruit breeding, vol 8, Handbook of plant breeding. Springer, Heidelberg, pp 697-728

Sosinski B, Gannavarapu M, Hager LD, Beck LE, King GJ, Ryder CD, Rajapakse S, Baird WV, Ballard RE, Abbott AG (2000) Characterization of microsatellite markers in peach (Prunus persica (L.) Batsch). Theor Appl Genet 101:421-428

Tavassolian I, Rabiei G, Gregory D, Mnejja M, Wirthensohn MG, Hunt PW, Gibson JP, Ford CM, Sedglev M, Wu SB (2010) Construction of an almond linkage map in an Australian population Nonpareil $x$ Lauranne. BMC Genomics 11:551

Testolin R, Marrazzo T, Cipriani G, Quarta R, Verde I, Dettori T, Pancaldi M, Sansavini S (2000) Microsatellite DNA in peach (Prunus persica (L.) Batsch) and its use in fingerprinting and testing the genetic origin of cultivars. Genome 43:512-520

Van Ooijen JW, Boer MP, Jansen RC, Maliepard C (2002) MapQTL Version 4.0, Software for the calculation of QTL positions on genetic maps. Plant Research International, Wageningen

Voorrips RE (2000) MapChart: software for the graphical presentation of linkage maps and QTLs. J Hered 93:77-78

Yamamoto T, Mochida K, Imai T, Shi IZ, Ogiwara I, Hayashi T (2002) Microsatellite markers in peach (Prunus persica (L.) Batsch) derived from an enriched genomic library and cDNA libraries. Mol Ecol Notes 2:298-302

Zhang G, Sebolt AM, Sooriyapathirana S, Wang D, Bink M, Olmstead JW, lezzoni A (2010) Fruit size QTL analysis of an F1 population derived from a cross between a domesticated sweet cherry cultivar and a wild forest sweet cherry. Tree Genet Genome 6:25-36 
TABLE 1

SSRs used for identification of QTLs in the almond cross "Vivot" × "Blanquerna"

\begin{tabular}{|c|c|c|c|c|c|c|c|}
\hline $\begin{array}{l}\text { Species } \\
\text { of origin }\end{array}$ & SSR name & Reference & $\begin{array}{l}\text { No. of } \\
\text { SSRs } \\
\text { tested }\end{array}$ & $\begin{array}{l}\text { No. of SSRs } \\
\text { amplified }\end{array}$ & $\begin{array}{l}\text { No. of } \\
\text { SSRs } \\
\text { mapped }\end{array}$ & $\begin{array}{c}\text { No of loci } \\
\text { mapped }\end{array}$ & $\begin{array}{c}\text { Percentage of } \\
\text { total SSRs placed } \\
\text { in the "V } \times \text { B" } \\
\text { map }\end{array}$ \\
\hline Peach & ВРPCT & $\begin{array}{l}\text { Dirlewanger et al. } \\
\text { (2002) }\end{array}$ & 24 & 23 & 15 & 16 & 28 \\
\hline Peach & СРРСТ & $\begin{array}{l}\text { Aranzana et al. } \\
(2002)\end{array}$ & 32 & 31 & 15 & 15 & 27 \\
\hline $\begin{array}{l}\text { Jap. } \\
\text { plum }\end{array}$ & CPSCT & $\begin{array}{l}\text { Mnejja et al. } \\
(2004)\end{array}$ & 6 & 6 & 6 & 6 & 12 \\
\hline Almond & EPDCU & $\begin{array}{l}\text { Howad et al. } \\
\text { (2005) }\end{array}$ & 6 & 6 & 2 & 2 & 3 \\
\hline Peach & EPPCU & $\begin{array}{l}\text { Howad et al. } \\
\text { (2005) }\end{array}$ & 9 & 9 & 1 & 1 & 2 \\
\hline Peach & PCHGMS/MaO & $\begin{array}{l}\text { Sosinski et al. } \\
(2000) ; \\
\text { Yamamoto et al. } \\
(2002)\end{array}$ & 5 & 5 & 2 & 2 & 4 \\
\hline Peach & UDP & $\begin{array}{l}\text { Cipriani et al. } \\
\text { (1999); Testolin et } \\
\text { al. (2000) }\end{array}$ & 17 & 17 & 9 & 9 & 15 \\
\hline Cherry & Others & $\begin{array}{l}\text { Cantini et al. } \\
\text { (2001); Downey } \\
\text { and lezzoni (2000) }\end{array}$ & 11 & 9 & 6 & 6 & 9 \\
\hline - & Total & - & 110 & 106 & 56 & 57 & 100 \\
\hline
\end{tabular}


TABLE 2

Basic statistics for nut and kernel traits in the "Vivot" $\times$ "Blanquerna" almond mapping population

\begin{tabular}{|c|c|c|c|}
\hline Trait & Minimum & Maximum & Mean \pm SD \\
\hline \multicolumn{4}{|l|}{ Nut } \\
\hline Width (W), mm & 13.89 & 26.87 & $20 \pm 2.4$ \\
\hline Thickness $(T)$, mm & 10.85 & 17.39 & $14.36 \pm 1.2$ \\
\hline Length (L), mm & 19.84 & 39.68 & $27.53 \pm 3.5$ \\
\hline Weight, g & 1.21 & 7.2 & $3.48 \pm 0.9$ \\
\hline Geometric diameter (GD), mm & 997 & 5581 & $2711 \pm 132$ \\
\hline Spherical index (SI) & 50.2 & 149.9 & $96.7 \pm 9.5$ \\
\hline Size, $\mathrm{mm}^{3}$ & 2991 & 16743 & $8134 \pm 635$ \\
\hline L/W & 0.53 & 0.88 & $0.73 \pm 0.08$ \\
\hline $\mathrm{T} / \mathrm{L}$ & 0.4 & 0.68 & $0.53 \pm 0.06$ \\
\hline$W / L$ & 0.62 & 0.8 & $0.72 \pm 0.04$ \\
\hline \multicolumn{4}{|l|}{ Kernel } \\
\hline Width (W), mm & 9.1 & 16 & $12.1 \pm 1.5$ \\
\hline Thickness (T), mm & 5.24 & 8.14 & $6.95 \pm 0.6$ \\
\hline Length (L), mm & 15.9 & 26.5 & $19.8 \pm 2.3$ \\
\hline Weight, g & 0.26 & 1.89 & $1.12 \pm 0.34$ \\
\hline Geometric diameter (GD), mm & 334.8 & 895.8 & $559.9 \pm 102$ \\
\hline Spherical index (SI) & 21 & 35.9 & $28.1 \pm 3.7$ \\
\hline Size, $\mathrm{mm}^{3}$ & 1005 & 2687 & $1679 \pm 347$ \\
\hline L/W & 0.43 & 0.74 & $0.62 \pm 0.07$ \\
\hline$T / L$ & 0.25 & 0.5 & $0.36 \pm 0.05$ \\
\hline$W / L$ & 0.36 & 0.79 & $0.58 \pm 0.09$ \\
\hline
\end{tabular}


TABLE 3

Putative QTLs identified in the "Vivot" × "Blanquerna" almond mapping population, the linkage group they mapped to, LOD score, closest marker, and the percentage of phenotypic variance explained by each QTL

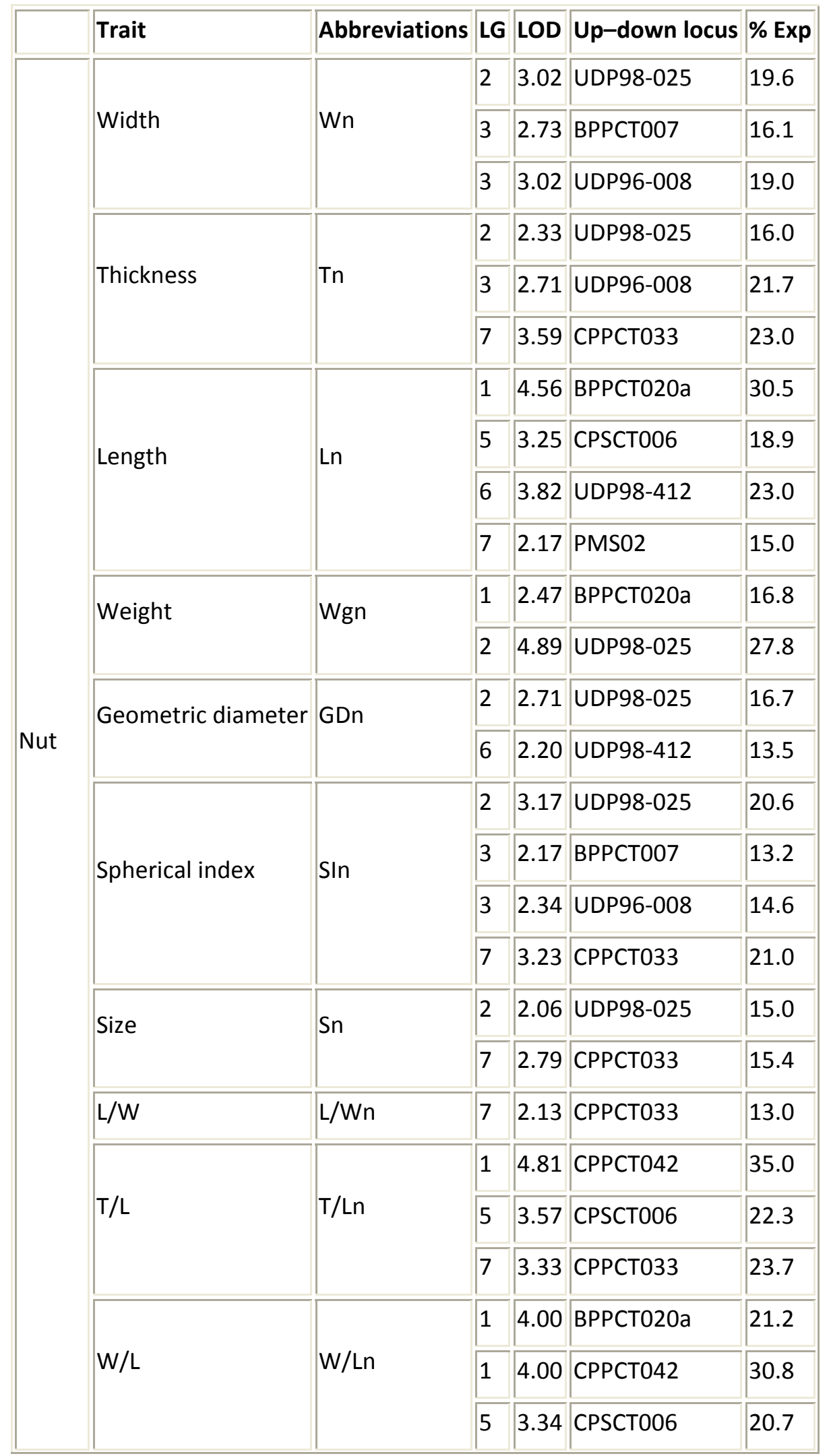




\begin{tabular}{|c|c|c|c|c|c|c|}
\hline & Trait & Abbreviations & LG & LOD & Up-down locus & $\% \operatorname{Exp}$ \\
\hline & & & 7 & 3.45 & СРРСТ0З3 & 23.8 \\
\hline & Width & Wk & 3 & 4.63 & UDP96-008 & 30.6 \\
\hline & & & 5 & 2.44 & ВРРСТ017 & 17.0 \\
\hline & & & 6 & 2.42 & ВРРСТ020b & 13.5 \\
\hline & Thickness & Tk & 6 & 2.86 & UDP98-412 & 24.2 \\
\hline & & & 7 & 3.02 & СРРСТ039 & 16.1 \\
\hline & & & 1 & 3.85 & СРРСТ042 & 27.2 \\
\hline & Length & Lk & 5 & 3.85 & СРSСТ006 & 16.8 \\
\hline & & & 6 & 2.48 & UDP98-412 & 23.6 \\
\hline & & & 7 & 2.13 & PMSO2 & 16.4 \\
\hline Kernel & Weight & Wgk & 7 & 2.90 & СРCST004 & 14.4 \\
\hline & Geometric diameter & GDk & 1 & 2.10 & ВРРСТ020а & 13.1 \\
\hline & & & 7 & 3.12 & СРРСТ0З3 & 18.6 \\
\hline & Spherical index & SIk & 7 & 2.80 & СРРСТ0З3 & 16.9 \\
\hline & Size & Sk & 7 & 3.19 & СРРСТ0З3 & 16.2 \\
\hline & & & 2 & 3.70 & UDP96-013 & 19.7 \\
\hline & L/W & L/Wk & 3 & 5.17 & UDP96-008 & 44.0 \\
\hline & & & 6 & 2.58 & ВРРСТ020b & 13.0 \\
\hline & $T / L$ & T/Lk & 1 & 4.40 & СРРСТ042 & 30.0 \\
\hline & & & 2 & 3.10 & UDP96-013 & 19.6 \\
\hline & $W / L$ & W/Lk & 7 & 4.30 & СРРСТ033 & 22.7 \\
\hline
\end{tabular}




\begin{tabular}{|c|c|c|c|c|c|c|c|c|c|c|c|c|c|c|c|c|c|c|c|c|}
\hline Trait & $\mathbf{W n}$ & $\mathrm{Tn}$ & Ln & Wgn & GDn & SIn & Sn & LWn & TLn & WLn & Wk & Tk & Lk & Wgk & GDk & Slk & Sk & LWk & TLk & WLk \\
\hline Wn & - & $0.88 * *$ & $0.64^{* *}$ & $0.89 * *$ & $0.93^{* *}$ & $0.98^{* *}$ & $0.93 * *$ & $-0.63 * *$ & -0.04 & $0.28^{*}$ & $0.95^{* *}$ & $-0.33^{* *}$ & $0.45^{* *}$ & $0.31^{*}$ & $0.68^{* *}$ & $0.63^{* *}$ & $0.68^{* *}$ & $-0.86 * *$ & $-0.51^{* *}$ & $0.48^{*}$ \\
\hline $\mathrm{Tn}$ & & - & $0.52 * *$ & $0.82^{* *}$ & $0.85^{* *}$ & $0.95^{* *}$ & $0.85^{* *}$ & -0.18 & -0.20 & $0.31 *$ & $0.85 * *$ & -0.15 & $0.34 * *$ & $0.30 *$ & $0.63^{* *}$ & $0.67^{* *}$ & $0.63^{* *}$ & $-0.70 * *$ & $-0.32^{* *}$ & $0.51^{* *}$ \\
\hline Ln & & & - & $0.77^{* *}$ & $0.84 * *$ & $0.61 * *$ & $0.84^{* *}$ & $-0.44^{*}$ & $-0.73 * *$ & $-0.55^{* *}$ & $0.57^{* *}$ & 0.11 & $0.93 * *$ & $0.41^{* *}$ & $0.78^{* *}$ & $0.36^{* *}$ & $0.78^{* *}$ & $-0.49 * *$ & $-0.81 * *$ & $-0.31^{*}$ \\
\hline Wgn & & & & - & $0.94^{* *}$ & $0.89 * *$ & $0.94^{* *}$ & $-0.59 * *$ & -0.02 & 0.01 & $0.83^{* *}$ & $0.31 * *$ & $0.59 * *$ & $0.47^{* *}$ & $0.71^{*}$ & $0.54 * *$ & $0.71^{* *}$ & $-0.75 * *$ & $-0.60 * *$ & 0.24 \\
\hline GDn & & & & & - & $0.94 * *$ & $0.99 * *$ & $-0.51 * *$ & $-0.27^{*}$ & -0.03 & $0.88^{* *}$ & $0.29 *$ & $0.68 * *$ & $0.36^{* *}$ & $0.80 * *$ & $0.61^{* *}$ & $0.80^{* *}$ & $-0.76 * *$ & $-0.64^{* *}$ & 0.22 \\
\hline SIf & & & & & & - & $0.94^{* *}$ & $-0.46 * *$ & 0.05 & $0.30 *$ & $0.93 * *$ & $-0.27^{*}$ & $0.42 * *$ & $0.30 * *$ & $0.69 * *$ & $0.66^{* *}$ & $0.68^{* *}$ & $-0.81 * *$ & $-0.45^{* *}$ & $0.50^{* *}$ \\
\hline Sn & & & & & & & - & $-0.51^{* *}$ & $-0.27^{*}$ & -0.03 & $0.88^{* *}$ & $-0.28^{*}$ & $0.68 * *$ & $0.36^{* *}$ & $0.80 * *$ & $0.61^{* *}$ & $0.80^{* *}$ & $-0.76^{* *}$ & $-0.64 * *$ & 0.21 \\
\hline LWn & & & & & & & & - & $0.39 * *$ & -0.10 & $-0.55^{* *}$ & $0.44^{* *}$ & $-0.36^{* *}$ & 0.14 & $-0.35^{* *}$ & 0.20 & $-0.35^{* *}$ & $0.64 * *$ & $0.54^{* *}$ & -0.16 \\
\hline TLn & & & & & & & & & - & $0.88^{* *}$ & 0.12 & 0.18 & $-0.79 * *$ & 0.22 & $-0.36^{* *}$ & 0.14 & $-0.36^{* *}$ & 0.03 & $0.71^{* *}$ & $0.77 * *$ \\
\hline WLn & & & & & & & & & & - & $0.32 * *$ & 0.03 & $-0.66^{* *}$ & 0.01 & -0.20 & $0.26^{*}$ & -0.21 & $-0.30 * *$ & $0.48 * *$ & $0.91^{* *}$ \\
\hline Wk & & & & & & & & & & & - & $0.35 *$ & $0.44^{* *}$ & $0.29 *$ & $0.75^{*}$ & $0.75^{* *}$ & $0.75^{* *}$ & $-0.84 * *$ & $-0.44^{* *}$ & $0.55^{* *}$ \\
\hline Tk & & & & & & & & & & & & - & $0.42^{*}$ & 0.21 & 0.22 & $0.47 * *$ & 0.22 & $0.70^{* *}$ & $0.67 * *$ & -0.09 \\
\hline Lk & & & & & & & & & & & & & - & $0.43 * *$ & $0.79 * *$ & $0.32^{*}$ & 0.79* & $-0.34 * *$ & $-0.79 * *$ & $-0.50 * *$ \\
\hline Wgk & & & & & & & & & & & & & & - & $0.51^{* *}$ & $0.40^{* *}$ & $0.51 * *$ & -0.10 & -0.19 & -0.11 \\
\hline GDk & & & & & & & & & & & & & & & - & $0.83^{* *}$ & 0.99* & $-0.40 * *$ & $-0.43^{* *}$ & 0.002 \\
\hline SIk & & & & & & & & & & & & & & & & - & $0.83^{* *}$ & $-0.30^{*}$ & 0.07 & $0.44^{* *}$ \\
\hline Sk & & & & & & & & & & & & & & & & & - & $-0.40 * *$ & $-0.43^{* *}$ & 0.002 \\
\hline LWk & & & & & & & & & & & & & & & & & & - & $0.65^{* *}$ & $-0.48 * *$ \\
\hline TLk & & & & & & & & & & & & & & & & & & & - & $0.34^{* *}$ \\
\hline WLk & & & & & & & & & & & & & & & & & & & & - \\
\hline
\end{tabular}




\section{TABLE 5}

Phenotypic correlations between chemical and physical traits of almond nut and kernel

\begin{tabular}{|c|c|c|c|c|c|c|c|c|c|c|c|c|c|c|c|c|c|c|c|c|}
\hline Trait $^{a}$ & Wn & Tn & Ln & Wgn & GDn & SIn & Sn & LWn & TLn & WLn & Wk & Tk & Lk & Wgk & GDk & SIk & Sk & LWk & TLk & WLk \\
\hline Protein & $-0.34 *$ & $-0.38^{*}$ & $0.61^{*}$ & $0.51^{*}$ & $0.52 * *$ & $-0.39 *$ & $0.52 *$ & -0.15 & $-0.39 *$ & $-0.34 *$ & -0.34 & 0.12 & $0.63^{*}$ & $0.37 *$ & $0.63^{*}$ & $0.40^{*}$ & $0.63 *$ & -0.18 & $-0.39 *$ & $-0.26 *$ \\
\hline Oil & $-0.29 *$ & $-0.25^{*}$ & $0.42 *$ & $0.29 *$ & $-0.38^{*}$ & $-0.30 *$ & $0.38 *$ & 0.16 & $0.26^{*}$ & 0.19 & -0.27 & 0.34 & $0.43^{*}$ & $0.36 *$ & -0.40 & -0.21 & $0.40^{*}$ & 0.19 & $0.33^{*}$ & 0.14 \\
\hline Oleic acid & $0.28 *$ & $0.40 * *$ & 0.02 & $0.24 *$ & 0.25 & $0.35^{* *}$ & 0.25 & 0.06 & $0.30 *$ & $0.29 *$ & $0.29 *$ & 0.03 & 0.03 & 0.03 & 0.16 & $0.27 *$ & 0.16 & 0.18 & 0.07 & $0.31 *$ \\
\hline Linoleic & $-0.27 *$ & $-0.38^{*}$ & -0.02 & -0.25 & -0.23 & $-0.33^{*}$ & -0.23 & -0.05 & $-0.28 *$ & $-0.27^{*}$ & -0.28 & -0.04 & -0.01 & -0.01 & -0.17 & -0.27 & -0.17 & -0.17 & -0.05 & $-0.30 *$ \\
\hline Stearic & $-0.47^{*}$ & -0.05 & $0.37 *$ & -0.22 & -0.24 & -0.08 & -0.24 & 0.04 & $-0.35^{*}$ & $-0.35 *$ & -0.36 & -0.60 & $0.38 *$ & 0.11 & -0.27 & -0.08 & $0.27 *$ & -0.03 & 0.21 & $-0.30 *$ \\
\hline Palmitolei & -0.25 & $-0.31^{*}$ & $0.28 *$ & -0.16 & -0.09 & $-0.30 *$ & -0.09 & -0.004 & $-0.57^{*}$ & $-0.62 *$ & -0.32 & 0.10 & $0.41^{*}$ & 0.02 & 0.09 & -0.23 & 0.09 & $0.28 *$ & $-0.27^{*}$ & $-0.49 *$ \\
\hline$\alpha-$ & 0.22 & 0.12 & 0.11 & 0.21 & 0.09 & 0.18 & 0.19 & -0.24 & -0.02 & 0.10 & 0.15 & -0.29 & -0.01 & -0.01 & -0.03 & -0.06 & -0.03 & -0.25 & -0.15 & 0.14 \\
\hline $\mathrm{Y}^{-}$ & 0.10 & -0.07 & 0.11 & 0.08 & 0.09 & 0.04 & 0.09 & $-0.30 *$ & -0.18 & -0.04 & 0.05 & -0.27 & 0.02 & 0.02 & -0.08 & -0.14 & -0.09 & -0.15 & -0.17 & 0.02 \\
\hline
\end{tabular}

Significant correlations are indicated by $* \mathrm{P} \leq 0.05$ and $* * P \leq 0.01$

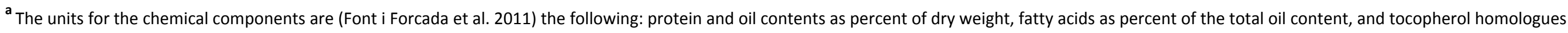
as milligrams per kilogram of oil 
FIGURE 1

Frequency distribution of the 10 nut physical traits studied for the individuals of the 'VÍB' population. Abbreviations of the traits are defined in TABLE 2. Values for parents are indicated by arrows (unfilled indicate Vivot; filled indicate Blanquerna)
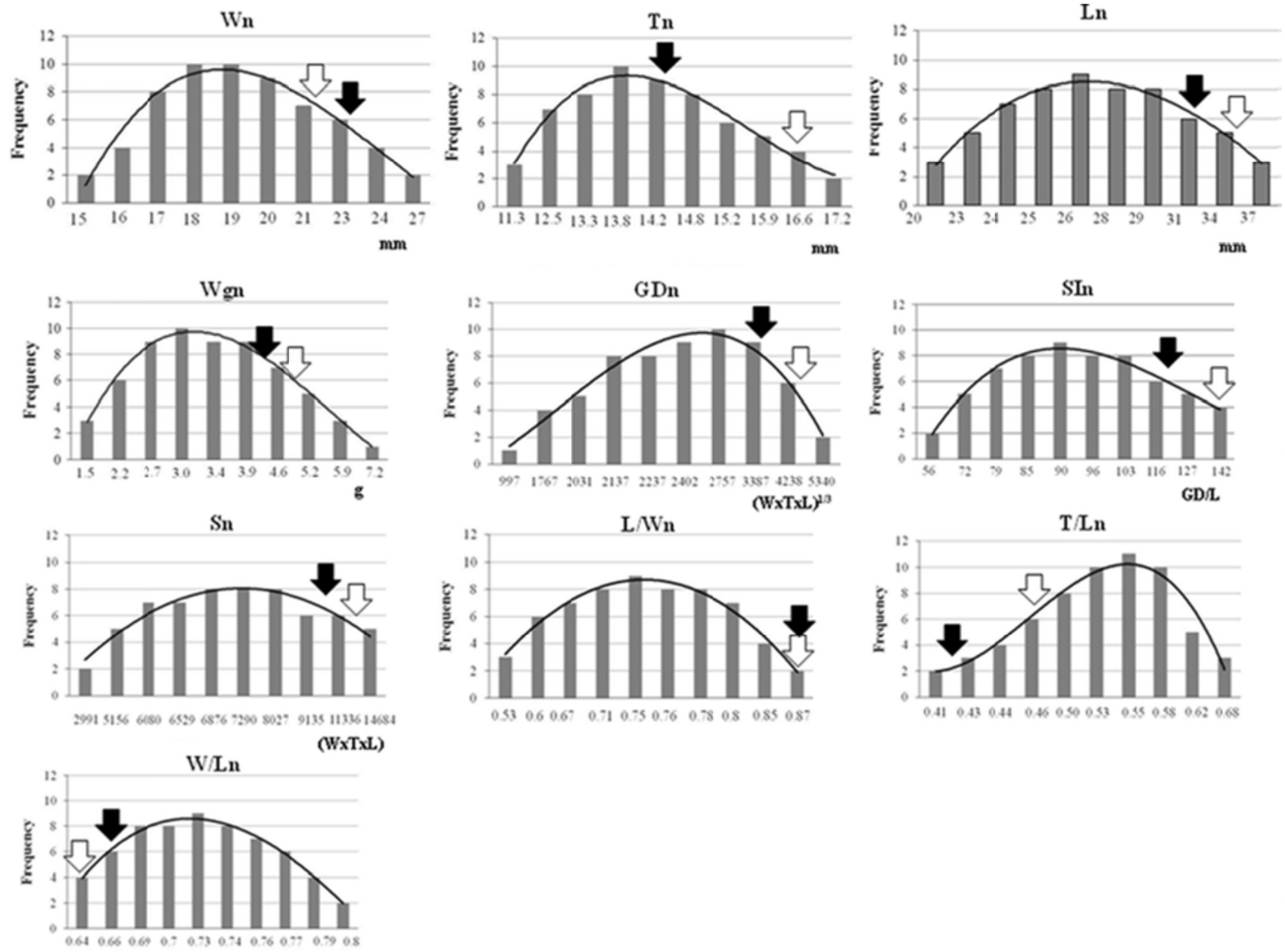
FIGURE 2

Frequency distribution of the 10 kernel physical traits studied for the individuals of the 'VÍB' population. Abbreviations of the traits are defined in TABLE 2. Values for parents are indicated by arrows (unfilled indicate Vivot; filled indicate Blanquerna)

Wk

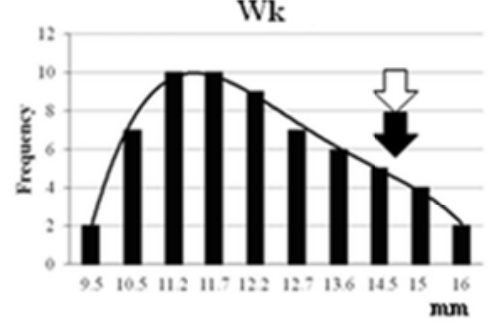

Wgk

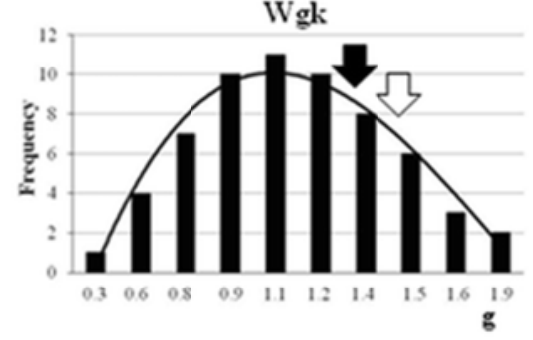

Sk
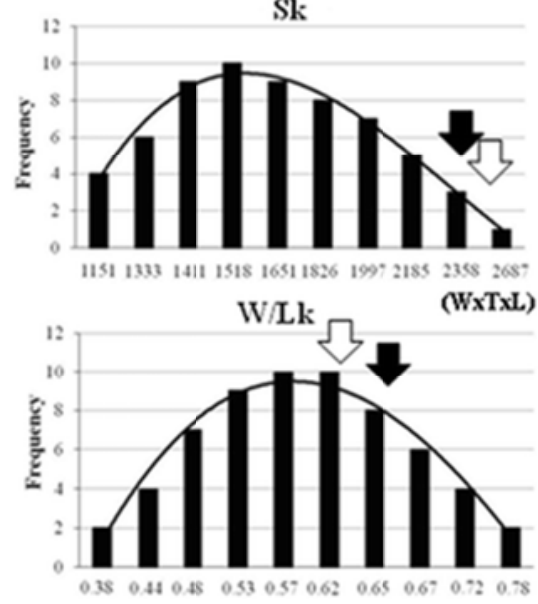

$\mathrm{Tk}$

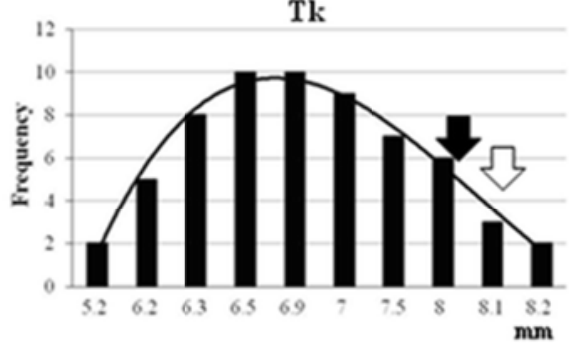

GDk

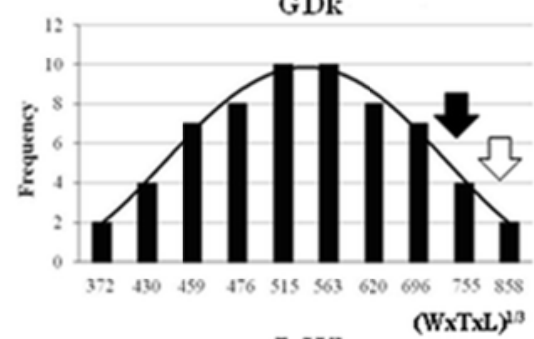

$\mathrm{L} / \mathrm{Wk}$

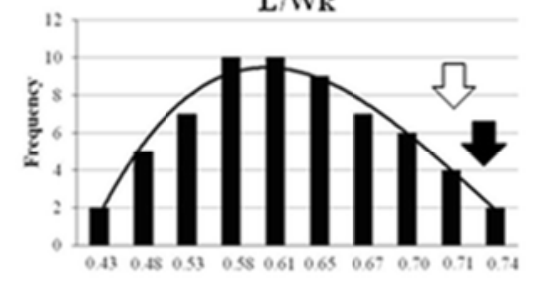

Lk

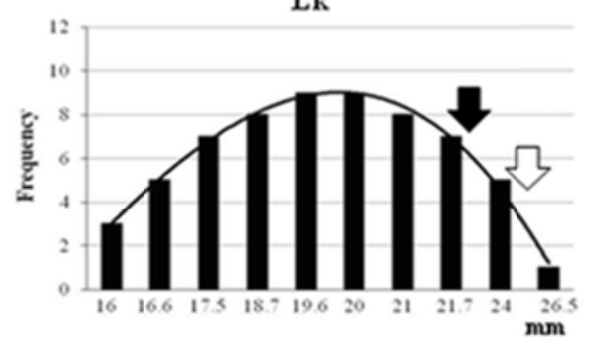

Snk

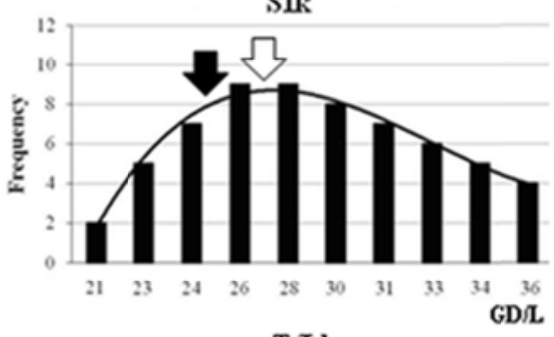

$\mathrm{T} / \mathrm{Lk}$

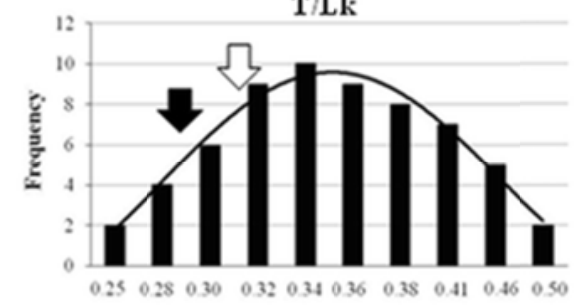




\section{FIGURE 3}

Combined linkage map of 'Vivot' I 'Blanquerna' population constructed using MAPCHART V. 2.1 (Voorrips 2000) showing putative QTLs associated with physical nut and kernel traits in almond. Abbreviations of the traits are defined in TABLE 2
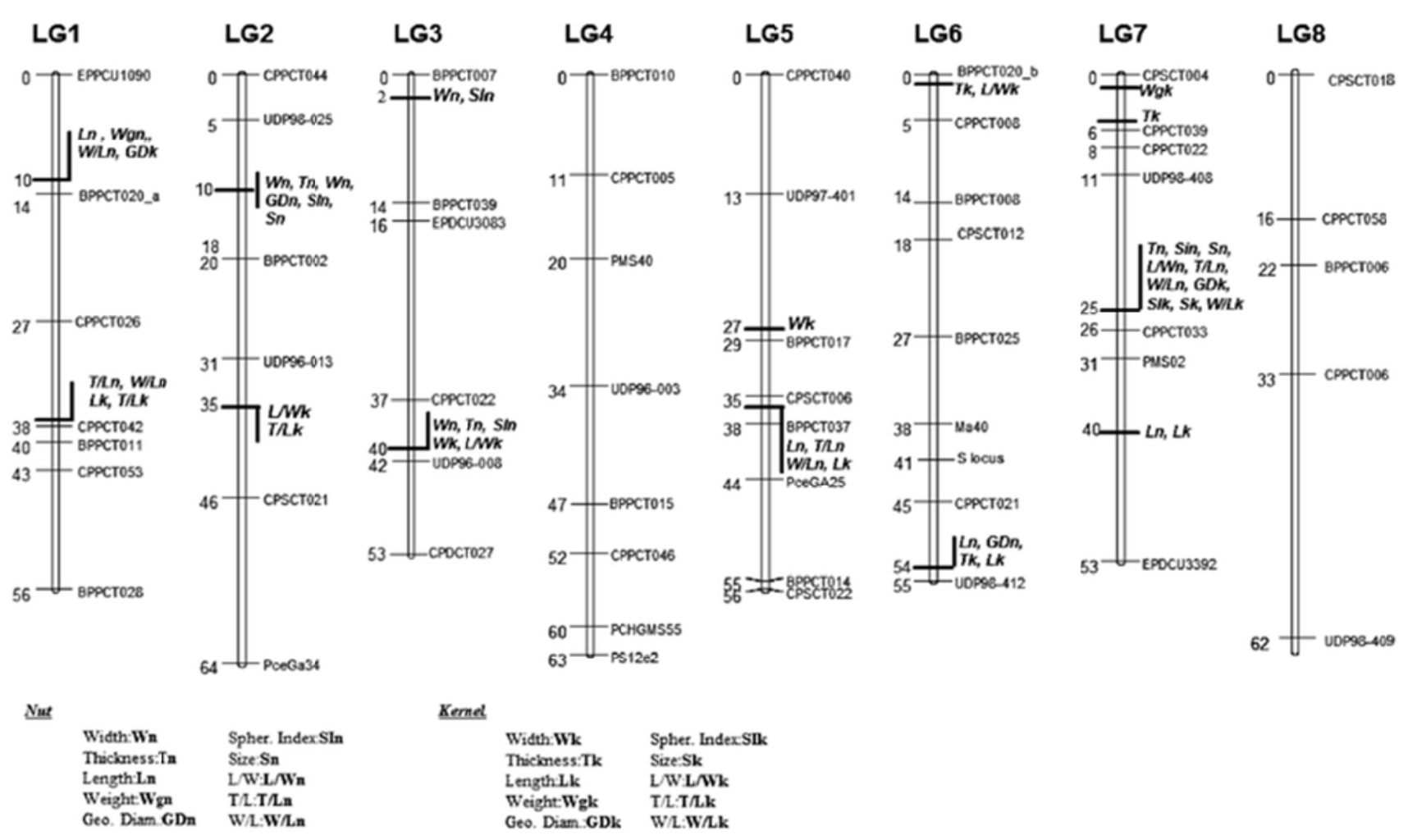